\title{
KIRJAVAHETUSTE KADUV MAAILM
}

Epistolaariume ehk kirjavahetusi võib vaadelda kui ühiskonna (kirja)kultuurilist infrastruktuuri, kultuuris endas aga kui n-ö sisekommunikatsiooni üht vormi teiste, näiteks pärimuste, kuulujuttude, anekdootide jms kõrval. Selle vormi žanriline ja funktsionaalne mitmekesisus (armastuskirjadest tarbekirjadeni; erinevas positsioonis ja suhetes subjektide, ameti- või loovisikute, armukeste või sõprade, õpetajate ja õpilaste jne vaheline kirjavahetus jms) ei väära asjaolu, et ajaloo- või kultuurilooliseks tekstiks muutuvad kirjavahetused alles post factum, pärast nende avaldamist. Juri Lotman, kelle kirju on Lotmani kolleeg Boriss Jegorov pidanud „andekateks” ning „paljužanrilisteks” teosteks ${ }^{1}$, on koos Aleksandr Pjatigorskiga rõhutanud „teksti” juures väljenduslikkust ${ }^{2}$. Avaldatud kirjavahetus omandab teksti staatuse, suhtudes avaldamata kirjadesse kui mitte-teksti.

Muidugi mõjutavad kirjavahetused sedasama ühiskonda ja kultuuri ka varjatult, aga nende mõjukuse määrast saadakse teada ikkagi pärast kirjade või kirjavahetuste juhuslikku ilmsiks tulekut või eesmärgistatud avaldamist. Sinnamaani on iga kirjavahetus intiimne akt, isiklik ja ainult asjaosalistele teada tegu. Eredaks näiteks sobib eesti kultuuri, aga ka rahvuse kujunemise seisukohast F. R. Kreutzwaldi kirjavahetus XIX sajandi keskpaigas. Aastail 1847-1866 vahetatud kirju koondava

${ }^{1}$ Б. Егоров, О письмах Ю. М. Лотмана. - Ю. Лотман, Письма. 1940-1993. Москва: Языки русской культуры, 1997, lk 7.

2 J. L o t m a n, Kultuuritüpoloogiast. Tartu: Tartu Ülikooli Kirjastus, 2010, lk 87.
II köite eessõnas rõhutab koostaja ning toimetaja Mart Lepik, et „esmajärguliste ja teistegi Kreutzwaldi elu ja tegevuse kõrvalisemate küsimuste tundmaõppimiseks, nende valgustamiseks ja uurimiseks on käesolev kirjavahetuste köide ...põhiliseks ja asendamatuks allikaks". ${ }^{3}$ Kirju Jakob Hurdale, Johann Kölerile ja Carl Robert Jakobsonile sisaldava VI köite eessõnas tõdevad koostajad Eeva Aaver, Heli Laanekask ja Abel Nagelmaa Kreutzwaldi suunavat ja õhutavat osa rahvuslikus liikumises. ${ }^{4}$

Kui me neid kirju ei loeks, siis jääks paljuski puudulikuks ka nende hoovuste fikseerimine, milles toimus eesti rahvusliku identiteedi konstrueerimine. Kirjavahetuse toimetajad möönavadki, et kuna vastuskirjad Kreutzwaldile VI köites puuduvad, mille põhjuseks võis olla, et Kreutzwald vanas eas need ise hävitas, siis jääb see osa kirjavahetusruumist monoloogiliseks. ${ }^{5}$ Kreutzwaldi ja Koidula kirjavahetust lähemalt uurinud Aino Undla-Põldmäe on näidanud, kuidas tänu kirjavahetusele Kreutzwaldiga küpses Koidula loojaks, kellena Eesti teda tänaseni tunneb. Kreutzwaldi eeskuju Koidula loomingule oli mitmetine, aga nagu Undla-Põldmäe tõdeb, vihjates diskreetselt kirjavahetuse intiimsemalegi poolele, „on siiras rõõm suurest andest

${ }^{3}$ M. Le pik, Eessõna. - Fr. R. Kreutzwaldi kirjavahetus II. Kirjad A. H. Neusile, E. Sachssendahlile ja teistele. 1847-1866. Tallinn: Eesti Riiklik Kirjastus, 1956, lk 5.

4 Fr. R. Kreutzwaldi kirjavahetus VI. Kirjad J. Hurdale, J. Kölerile, C. R. Jakobsonile ja teistele. 1862-1882. Koost E. Aaver, H. Laanekask, A. Nagelmaa. Tallinn: Eesti Raamat, 1979, lk 5.

${ }^{5}$ Fr. R. Kreutzwaldi kirjavahetus VI, lk 5. 
heletanud tema [Kreutzwaldi $-R . V$.] meelt."

Kui 1990. aastal ilmus Helgi Vihma koostatud ja kommenteeritud Johannes Aaviku ja Friedebert Tuglase kirjavahetus, siis rõhutas juba raamatu pealkiri „Kultuurilugu kirjapeeglis” kirjavahetus(t)e tähtsust kultuuriloolises uurimises. Ja mitte ainult. Eesti kirjandusliku mõtte arengut võib jälgida Ants Orase ja Ivar Ivaski („Akadeemia kirjades”, 1997) ning Karl Ristikivi ja Bernard Kangro („Kirjad romaanist”, 1. trükk 1985, 2. trükk 2006) kirjavahetuste vahendusel. Eesti kirjandus- ja kultuurielu kahe sõja vahelisel perioodil leiab seestpoolt valgustamist Artur Adsoni ja Friedebert Tuglase kirjavahetuses („Paaži ja Felixi kirjavahetus”, 2011), Välis-Eesti „sise-elu” kommentaariumi võib lugeda Arvo Mägi ja Arno Vihalemma kirjadest („Kord Vihalemm elas Ystadis”, 2000), Välis- ja Kodu-Eesti „sillal” toimuvast Hellar Grabbi ja Jaan Kaplinski kirjavahetusest („Sõprade kirjad on su poole teel”, 2013). Kirjavahetustest kui kultuuri sisepeegeldustest võiks küllap rääkida teistegi, siin veel nimetamata kirjavahetuste puhul.

Ent aja- ning kultuuriloolise fakti kõrval osalevad avaldatud kirjavahetused nagu ka (auto)biograafiad n-ö elu(loo) legitimatsioonis. Juri Lotman on seda protsessi artiklis „Õigus biograafiale” kirjeldanud nii: „...kogu inimmassist, kelle elukäik ei kuulu kirjeldamisele ja kollektiivsesse mällu salvestamisele, valitakse keegi, kelle nimi ja teod säilitatakse järeltulevatele põlvedele." Ilmi Kolla kirju uurinud Eve Annuk rõhutab kirjavahetuste olulisust elulugude uurimisel. ${ }^{8}$ Nii avaneb elav inimene tekstide

6 A. Undla-Põldmäe, Koidulauliku valgel. Tallinn: Eesti Raamat, 1981, lk 100.

${ }^{7}$ J. L o tm a n, Kultuurisemiootika. Tekst - kirjandus - kultuur. Tallinn: Olion, 1991, lk 366.

${ }^{8}$ E. Annuk, Uurija rollist ja eetikast biograafilise uurimise kontekstis Ilmi Kolla kirjavahetuste näitel. - Võim \& kultuur 2. varjus. ${ }^{9}$ Autobiograafilise kirjanduse teoreetik Philippe Lejeune liigitab autobiograafia intiimkirjanduse alla, mille tunnuseks on autori, jutustaja ja tegelase identsus. ${ }^{10}$ See kehtib ka kirjavahetuste kohta. Kirja kirjutaja võib küll näha end tegelasena mingis (näiteks adressaadi) kontekstis, aga ta teeb seda ikkagi enda nimel. Eduard Vilde kirju Rahel Uschmarowile („Minu põsk sinu põse vastu”, 2015) kommenteerinud Kairi Tilga näitab, kuidas vana ja haige Vilde suhtleb oma kirjades korraga nii reaalse kui ka illusoorse partneriga ja kuidas selline intensiivne „tunnete pingpong” kurnab kirjaniku lõplikult. ${ }^{11}$ Vilde ja tema armastatu kirjavahetuse avaldamine on toonud Vilde elu- ja loomingu käsitlusse uue perspektiivi. Seda tuleb öelda ka seoses Betti Alveri ja Mart Lepiku kirjavahetuse („Minu lamp põleb”, 2015) avaldamisega, mis mõjub epistolaarse romaanina. Karl Ristikivi „Valitud kirju" (2002) arvustades on Toomas Liiv näinud neis samuti otsekui üht avaldamata romaani, omalaadset minientsüklopeediat Karl Ristikivi elu ja loomingu kohta. ${ }^{12}$ Muuhulgas tõdeb Liiv kirjadele olemuslikku enesevõõrandamist: „Kirja kirjutamine oli ja on rajatud alati vahemaale nii ajas kui ka ruumis, kaitsvale distantsile, vahendatuse, kirjutatuse, salvestatuse impersonaalsele ilule."13

Kultuuriikoonideks kujunenud isikute, nagu Vilde ja Alveri puhul pole kirjavahetuste avaldamine päriselt probleemitu. Kirjandus- ja laiemalt võttes kultuuriloolises uurimistöös on suhtutud kirjavahetustesse kui sekundaarsesse allikmaterjali. Alveri ja Lepiku kirja-

Koost Mare Kõiva. Tartu: Eesti Kirjandusmuuseum, 2006, lk 163.

${ }^{9}$ E. An nuk, Uurija rollist..., lk 170.

${ }^{10}$ P. L ej e u n e, Autobiograafiline leping. Methis 2010, nr 5/6, lk 198.

${ }^{11}$ K. Tilg a, Eessõna. - Minu põsk sinu põse vastu. Eduard Vilde kirjad Rahelile. Tallinn: Hea Lugu, lk 16.

${ }^{12}$ T. Li iv, Karl Ristikivi ja tema kirjad. Sirp 11. VII 2003.

${ }^{13}$ T. Li i v, Karl Ristikivi ja tema kirjad. 
vahetuse ilmutamist kommenteerinud Vallo Kepp leiab, et kui juba kirjavahetusi avaldada, siis tuleks seda teha, arvestades kirjade kaasaja konteksti. ${ }^{14}$ See eeldab laialdast joonealust kommentaariumi, aga ka kirjade koostaja/ avaldaja uurimuslikku saate- või järelteksti. Selliseks näiteks on 2015. aastal ilmunud Uku Masingu ja Toomas Pauli kirjavahetus „Usalda ennast”. Samal aastal Kairi Tilga koostatud, põgusalt kommenteeritud ning eessõnaga varustatud Eduard Vilde kirjades Rahel Uschmarowile võinuks Sirje Oleski arvates teha kupüüre. ${ }^{15}$ Olesk põhjendab seda kahe asjaoluga. Esiteks puuduvad Uschmarowi kirjad Vildele, mis tõenäoliselt on hävitatud, sest Vilde ei tahtnud, erinevalt Uschmarowist, jätta jälge oma „hilise armastuse õnnetusest”. Teiseks tekitavat mitmed kohad kirjades piinlikkust, asetades/alandades lugeja vuajeristi, „lukuaugupiiluja” positsioonile. Üks osa seltskonnaajakirjandusest, „kollaseks” nimetatu, aga töötabki just vuajeristlikul režiimil. (Üld)inimliku huvi (human interest) puhul, mis keskendub loomingu telgitaguste, looja isikuomaduste, tema harjumuste, söögi- ja joogikommete, käitumise jne iseloomustamisele, võidakse ületada just nimelt see „liigisiklikkuse” piirjoon, mille taga asuvad, piltlikult väljendudes, inimese intiimsed tagatoad.

Siinkohal ongi viimane aeg tunnistada, et rääkides kirjavahetustest kultuuri varjatud tegurina, räägin ma tegelikult juba kadunud või kaduvast maailmast. Maailmast, kus kirju tõepoolest kirjutati hane- või rauast sule, pliiatsi või pastapliiatsiga, suleti ümbrikutesse, varustati aadressi ja saatja aadressiga ning läkitati teele. Ja jäid seejärel kusagil aadressaadi sahtlites või arhiivides ootama avastamist, kultuurilist inkarnatsiooni. XXI sajandi sotsiaalmeedia (palgeraa-

\footnotetext{
${ }^{14}$ V. Ke p p, Betti Alveri ja Mart Lepiku laugjad read. - Sirp 27. XI 2015.

${ }^{15} \mathrm{~S}$. O le s k, Isiklik... liiga isiklik? - Keel ja Kirjandus 2016, nr 3, lk 223.
}

matud, blogid, kommentaariumid) ajastul on kirjavahetusteski leidnud aset paradigmaatiline muutus. Me „toksime” kirju arvutitesse (mis võimaldab kirjutamishetkel mõeldut-öeldut kustutada) ja lennutame neid seejärel klahviklõpsuga välgukiirusel elektroonilistele aadressidele. Mõned meist peavad simultaanseid kirjavahetusi (ühelt aadressilt paljudele, seda on muide ka palgeraamatu sissekanded). On kujuteldamatu, kui paljud seesugustest kirjavahetustest salvestatakse tulevase (kultuuri)ajaloo tarbeks ja kuhu need salvestatakse (Google’i „pilvedesse”, arvutimälu kõvaketastele?). Skeptikud väidavad, et salvestatud teksti digijälg vajab aeg-ajalt uuendamist; alati võib leiduda neid, kes „kirjakastidesse” häkivad või kirju n-ö vahelt lõikavad, et neid siis avalikustada. Keegi ei saa olla kindel ei kirjavahetuse säilimise ega ka kuuluvuse suhtes. Piirid era- ja avaliku sfääri vahel on muutunud õhkõrnaks. Toomas Liivi ülalpool tsiteeritud distantseerituse, vahendatuse, kirjutatuse, salvestatuse impersonaalse ilu vahetab välja mingi praktiline kaalutletus või teabevajadus. Kirjavahetuste subjektsus lahustub objektidevahelisse suhtlusse.

Siiski näeme ka elektroonilise kirjavahetuse sisenemist kirjanduse- ja kultuuriloolisele väljale. Pole erandiks, kui mõni kirjandusuurija viitab oma kolleegile või uuritavale autorile elektroonilise kirja kaudu. Seni pole veel juurde lisatud kontrollivõimalusena kirja enda elektroonilist aadressi. Viide toimib selle lugeja jaoks usalduskrediidina. Kui seda viidet aga hiljem kasutada, siis ollakse olukorras, kus allikas jääbki virtuaalseks. Kultuuris toimivate hoovuste rekonstrueerimine kirjavahetuste abil kujutab tulevikus endast pigem hõljumit kui kindlat, käegakatsutavat reaalsust. Nõnda olemegi jõudmas nii oma elu-, aja- kui ka kultuurilugudega fiktsionaalsusse.

REIN VEIDEMANN 